\title{
Pressure driven inside feed (PDI) hollow fibre filtration: Optimizing the geometry and operating parameters
}

\author{
Qian X $u^{a}$, Graeme K. Pearce ${ }^{b}$, Robert W. Field ${ }^{a}$, \\ a Department of Engineering Science, University of Oxford, Parks Road, Oxford, OX1 3PJ, \\ United Kingdom \\ ${ }^{b}$ Membrane Consultancy Associates, United Kingdom \\ ${ }^{*}$ Robert W. Field, Tel.:+44(0)1865 273181, E-mail:robert.field@eng.ox.ac.uk
}

\section{Research Highlights:}

$>$ Realistic pressure driven inside feed (PDI) hollow fibre filtration model developed.

$>$ Filtration performance is examined via module productivity and filtration uniformity.

$>$ Design guidelines for PDI modules are presented.

\section{Keywords:}

direct-flow filtration, hollow fibre membrane, fibre length, fibre diameter, void fraction

\begin{abstract}
:
Direct-flow filtration combines a filtration cycle operating in dead-end mode with regular intermittent backwashes. Such filtration module is achieved by efficiently capping one end of the crossflow device so that all the fluid is forced to pass through the membrane walls. This paper focuses on the operational considerations and design aspects of the direct-flow filtration membrane modules, specifically pressure driven inside feed (PDI) format. PDI is commonly used since it permits effective backwash and long term stability. The axial dependence of the transmembrane pressure (TMP) and the cumulative filtration volume is studied under non-fouling conditions. Geometrical parameters including fibre radius, fibre wall thickness, fibre length, module void fraction and imposed average flux are varied over a broad range values encompassing the values applied in today's water industry. Two performance parameters are introduced: the module productivity parameter, and the filtration uniformity factor. Suggested design ranges for fibre diameter, fibre length and packing density are given. Taguchi's method is applied to determine how much each parameter contributes to the overall filtration performance.
\end{abstract}




\section{Introduction:}

This section firstly introduces the concept and development of direct-flow filtration particularly with regard to drinking water treatment, together with some background details pertinent to this paper. Details of model development are presented in section 2, discussion and conclusions are given in sections 3 and 4 .

\subsection{Membrane filtration}

Ultrafiltration (UF) and microfiltration (MF) membranes have been widely used for water treatment since the 1980s [1-3]. The early stage membranes tended to be UF with a fine or medium pore size. These were for either process water filtration or ultra-pure water production. In the 1990s, coarser UF and MF membranes were developed for drinking water, and these same membranes were then utilized in RO pre-treatment applications for wastewater and seawater duties [4].

The present day water membrane industry is dominated by coarse UF with a pore size rating of around $0.02 \mu \mathrm{m}$ or fine MF with a pore size rating of 0.04 to $0.1 \mu \mathrm{m}$ [5]. Two materials have come to dominate the industry, namely polyethersulfone (PES) and polyvinyldene difluride (PVDF). Nearly all commercial products in the mainstream filtration duties in water treatment use membranes in the hollow fibre format since this has been found to provide the ideal combination of packing density, hydrodynamic efficiency, and integrity.

\subsection{Membrane filtration applications in drinking water treatment}

The expansion of the membrane market was driven by legislation for drinking water use which has led to a rapid uptake in membrane systems since 1998. The early products were expensive which tempted system designers to use high fluxes. Fouling tends to increase exponentially with flux [6], so many early plants faced challenging operational problems resulting from an excessive development of trans-membrane pressure. Furthermore, some of the early products were weaker than today's commercial offerings which led to integrity issues and occasional plant failures [7].

In recent years, membranes have improved, providing better permeability and strength. Also, system design has become more conservative with a tendency to select a more moderate design flux. Nevertheless, the lessons from those early experiences are still relevant since some applications pose serious fouling challenges. 


\subsection{Flow configuration}

Membrane filtration processes can be designed to operate in three ways: dead-end, crossflow, and direct-flow (Fig. 1). In classical dead-end filtration the flow and filtration direction are both normal to the membrane surface, while in crossflow mode the flow is parallel to the membrane surface with permeation being orthogonal to the feed flow [8]. The modern water membrane market is based on the use of Direct-flow, which combines a filtration cycle operated in dead end with a regular intermittent backwash. Direct-flow filtration offers an efficient combination of the benefits of both dead-end and crossflow filtration. During the filtration cycle, one end of the crossflow device is effectively capped so that all the fluid is forced to pass through the membrane walls. This is normally achieved through near-permanent closing of the relevant valve. To ensure sustainable operation short automatic backwashes at regular frequencies are incorporated to make fouling mainly reversible and typically the capped end remains closed. Direct-flow filtration is more energy efficient than crossflow filtration since the inflow velocity is modest because all of the feed is filtered. Thus the pressure drop along the feed channel during the filtration cycle can be very small. Also it permits the use of smaller diameter fibres which enables the filtration area per unit volume to be increased. It therefore forms the dominant method for producing potable water from ground or surface water [9]. A summary of flow configurations in three filtration formats is given in Table 1.

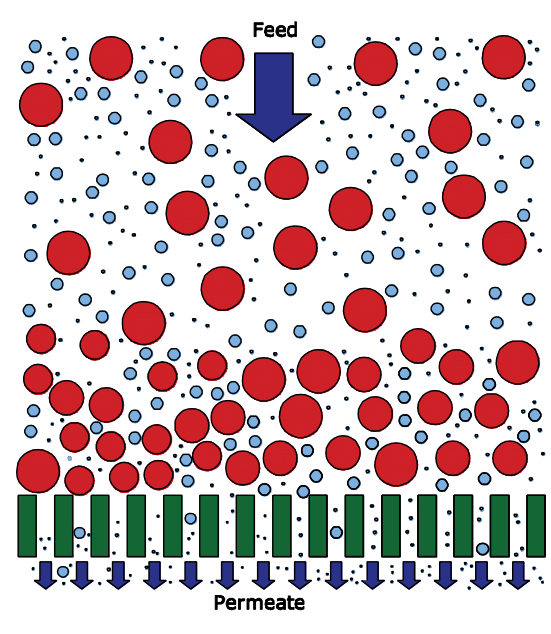

(a) Dead-end Flitration

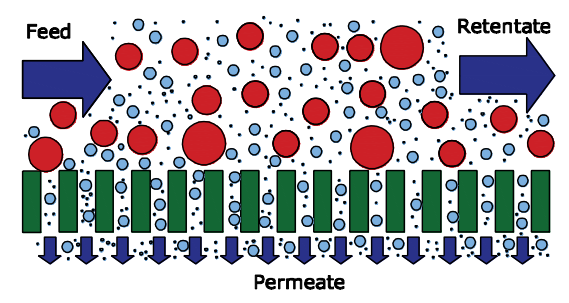

(b) Tangentlal (Crossflow) Filtration

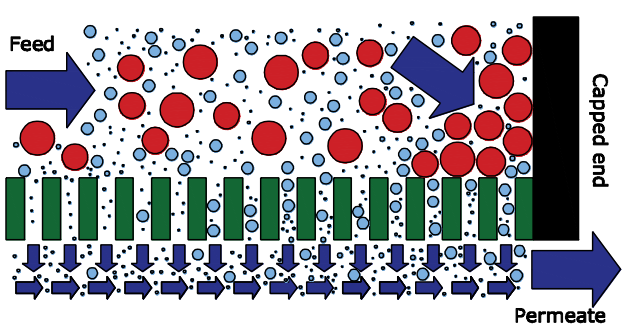

(c) Direct-flow Filtration

Fig. 1. Schematics of (a) dead-end, (b) crossflow and (c) direct-flow filtration. Please note in particular for (b) and (c) the aspect ratio (length/radius width) is not to scale. 
Table 1 Summary of flow situations in three filtration modes

\begin{tabular}{|c|c|c|c|}
\hline & Dead-end & Crossflow & Direct-flow \\
\hline Strength of feed flow & $\begin{array}{l}\text { Feed flow }= \\
\text { Permeate flow }\end{array}$ & $\begin{array}{l}\text { Feed flow } \gg \\
\text { Permeate } \\
\text { flow }\end{array}$ & $\begin{array}{l}\text { Feed flow }= \\
\text { Permeate flow }\end{array}$ \\
\hline Tangential flow & None & Yes, strong & $\begin{array}{l}\text { Yes, weak and } \\
\text { variable }^{1}\end{array}$ \\
\hline Permeate rate & $\begin{array}{l}\text { Low permeate } \\
\text { rate }\end{array}$ & $\begin{array}{l}\text { High } \\
\text { permeate } \\
\text { rate }\end{array}$ & $\begin{array}{l}\text { High net } \\
\text { permeate rate }\end{array}$ \\
\hline $\begin{array}{l}\text { Orientation of } \\
\text { permeate }\end{array}$ & $\begin{array}{l}\text { Same } \\
\text { direction }\end{array}$ & Orthogonal & Orthogonal \\
\hline $\begin{array}{l}\text { Means of reducing } \\
\text { fouling }\end{array}$ & None & $\begin{array}{l}\text { Shear due to } \\
\text { crossflow }\end{array}$ & $\begin{array}{l}\text { Frequent } \\
\text { periodic } \\
\text { backwashes }^{2}\end{array}$ \\
\hline
\end{tabular}

\subsection{Fouling mechanisms}

Particle removal technologies are prone to fouling because of the very challenge that they are trying to address. A simplified representation of the two main physical fouling mechanisms is shown in Fig. 2. If the pore or aperture openings of the filtration media are larger than the particles the particles may enter the throat of the pore and block it or severely restrict the flow through it. Additionally a high concentration of particles of different sizes congregating near the pore openings may cause a cake layer to build-up. As the cake layer develops, it effectively becomes the filtration medium since it prevents particles approaching the surface.

\footnotetext{
${ }^{1}$ Tangential flow in direct-flow filtration exceeds weak and is towards moderate, but becomes strong in backwash.

${ }^{2}$ Backwash creates crossflow to reverse pore plugging and concentration polarization so that particles can be removed from both the pore throat and the cake layer.
} 


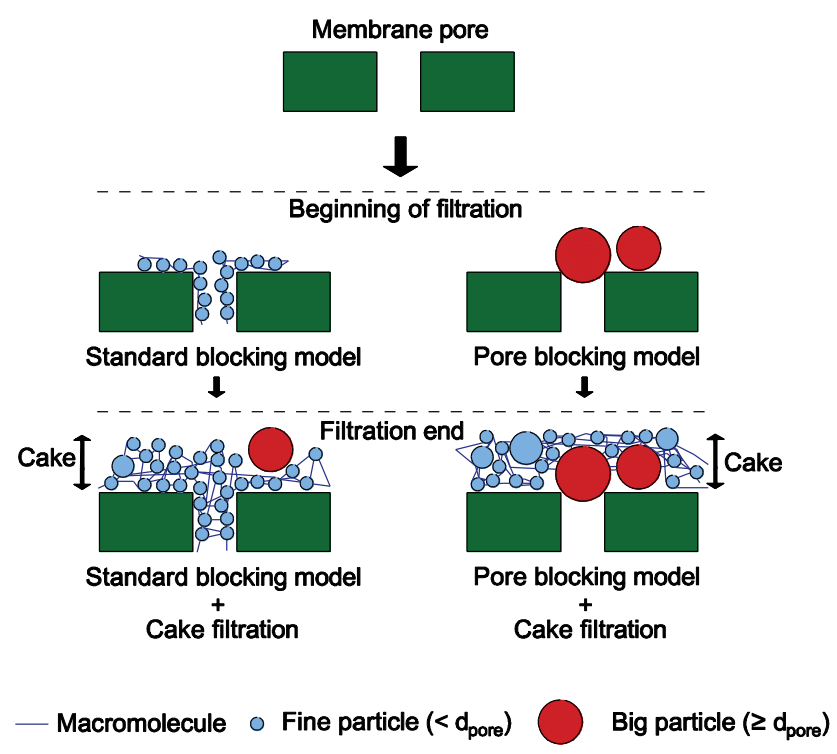

Fig. 2. Particle Fouling Mechanisms

A third type of fouling is due to the adsorption of molecules onto the membrane surface which may bind other foulants or restrict pore openings. Adsorptive fouling normally has to be removed by some form of chemical cleaning.

If feed flow is maintained constant, then the consequence of fouling (and incomplete cleaning) is that the differential pressure rises from cycle to cycle, either due to the restriction in the number of pores available, or due to the additional resistance of the developing cake layer, or a combination of both. The physical backwash process referred to in section 1.3 may remove more than $90 \%$ of the foulants, but it is not fully effective. On a fairly regular basis, chemicals will need to be added to enhance the cleaning efficiency, and periodically, a full clean-in-place procedure is required.

\subsection{Module format}

There are two types of membrane format and they are based on whether the feed is on the inside of the fibre lumen or on the outside. The formats are respectively known as pressure driven inside feed (PDI) and pressure driven outside feed (PDO). The inside feed format has the advantage of containing the contaminants from the feed in the fibre lumen and providing controlled hydrodynamics. The downside is that the surface area based on the inner diameter is much less than that based on the outer diameter. For the outside feed format, the advantages are tolerance of a high solids concentration in the feed and a higher surface area. The downside is that the hydrodynamics are spatially variable and not so easily controlled. To counter poor efficiency in backwash, outside feed 
formats utilise air scour during backwash which is effective, but adds another process operation.

An important variant of the outside feed configuration is to immerse bundles of fibres into a tank of the water to be treated, without module containment, and to apply a vacuum on the permeate side. This is known as the submerged format.

The different requirements of inside and outside feed formats has led to a different selection of polymer materials. Most inside feed products utilize polyethersulphone (PES) which has high permeability and good strength. The outside feed format is dominated by polyvinylidene fluoride (PVDF) which has good flexibility allowing it to tolerate air scour, but it has lower permeability. The surface area advantage of the outside feed format is somewhat lost by having to use a flexible material with lower permeability. In practice, the pros and cons of the two formats are therefore finely balanced and both approaches have strong adherents. Indeed, both types of product are strongly represented in the membrane market.

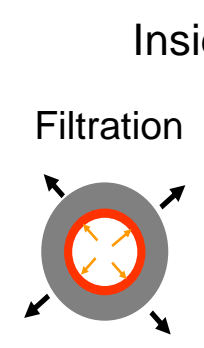

Inside Feed
Outside Feed

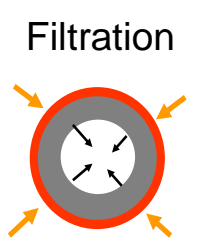

Key

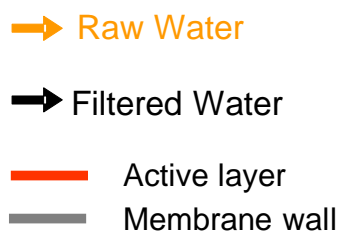

Fig. 3. Process flows of the two formats as seen in cross-section.

Fig. 3 shows that during the filtration cycle the fibre is subject to expansion due to the pressure of the feed. In backwash, the fibre is subject to compression. The reverse is true for the outside format. Expansion of the inside format during the filtration cycle will tend to enlarge the pores. If pressures are too high, fouling effects such as pore plugging may be enhanced. Conversely, the backwash operates typically at higher flow, perhaps 2.5 times that in the filtration cycle. Any foulants trapped in the pores during the filtration cycle may be hold by pinching due to slight contraction during backwash.

Commercial practice has shown that inside feed format plants operate well if pressures are kept low by using a moderate or conservative design flux. Under these conditions, backwash is effective and the plant has good long term stability. However, if the design flux is 
too high and pressures rise during a sequence of filtration cycles, the backwash pressures can quickly become excessive. The removal of foulants by backwash alone may be ineffective and irreversible fouling may develop. In the worst cases, the pressures could become so high that the fibre loses integrity, becoming crushed by pressure spikes [7].

Outside format plants also have limitations if pressures become too high, because the trans-membrane pressure can then rise sharply to display a characteristic saw-tooth pattern during the feed cycle. Additionally it may lead to compression of any cake filtration layer. Although the foulants may be effectively removed during the backwash/air scour cycle, energy and chemical costs can become excessive [10]. The problems for these plants are therefore not so much loss of integrity but excessive operational costs.

Some earlier plants of both formats suffered from problems since expensive membranes and inexperience encouraged the use of excessive design fluxes. Outside feed format plants suffered from excessive operational costs and inside feed formats could potentially suffer from integrity loss or require fibre repair procedures too frequently. When high design flux was combined with early stage product weakness, excessive fibre breakage could occur, and a small percentage of plants suffered from this specific problem.

These days, products have improved and fluxes tend to be lower, but challenging feeds can still raise concerns. For example episodes of poor feed water quality may combine with lower temperatures and/or temporary equipment failure (such as a sticking valve) to increase the stress on a plant. This paper therefore sets out to model the hydrodynamic efficiency of the inside feed format module. The ultimate aim is to identify operational triggers such as the maximum allowable filtration cycle pressure to ensure the long term operational resilience of these plants.

\subsection{Academic literature review}

Although many industrial projects have employed the direct-flow filtration format, there has been few published studies on the associated flow regimes and filtration behaviours. In particular there are limited entries for the PDI format as given in Table 2 which includes some results for crossflow. A recent mathematical study developed a dimensionless model to explore the variation in the axial dependency of TMP and predict the operating regimes of the device that maximize the spatial uniformity in TMP and thereby optimize the use of the entire membrane area [8]. However it did not take the wall thickness into account and covered a limited set of module geometric parameters. Nevertheless it did highlight that for PDI operation a large portion of the available membrane area is 
not used when the fibres are packed too closely together; in this case the majority of the filtration becomes localized near the impermeable cappedend. That paper introduced two performance parameters: (i) the uniformity of filtration was quantified through the parameter $\varphi$ and (ii) the module productivity was analysed mathematically through the parameter $\alpha$. The former is retained for use herein whilst the latter is more usefully re-defined as normalised module productivity, $\beta$, as given later in this section.

Now in hollow fibre (HF) membrane modules the wall thickness occupies a notable portion of the overall device space (circa $30 \%$ ) so in real engineering it influences the module performance. By building upon this mathematical model, but avoiding the thin wall assumption, this paper explores direct-flow filtration for a range of a realistic HF module dimensions and operating conditions for pressure driven inside flows.

In the literature there are a few attempts to analyse the influences of geometry of HF module design on the overall filtration behaviours mostly with regard to crossflow operation. Agreement has been reached that a shorter length fibre with larger lumen diameter is desirable so as to increase the filtration throughput per unit membrane area [11-16]. Long fibres with small inner diameters will generate large differences in local flux and leads to a rapid increase in transmembrane pressure [13, 14]. Additionally, any increase in fibre length beyond a certain value will lead to more non-uniform local flux distribution and severe membrane fouling [16]. Moreover, the negative effect of having longer fibres will be even worse at high module packing (low void fraction) because the filtration flux will decrease dramatically and filtration behaviour will occur preferentially at the capped end [17-19]. Therefore the effect of module packing (void fraction) to the filtration performance should not be ignored. Also the ratio of inside to outside fibre diameter has been shown to have an influence with the filtration productivity being different at various ratios $[11,20]$. This indicates the potential importance of fibre wall thickness. To date, although a general understanding has been achieved by researchers [11-23] that the geometry of the fibre as well as operating conditions is crucial to the membrane filtration efficiency, there remains the need for systematic modelling at full scale. In particular an understanding of the effects of fibre wall thickness, void fraction and imposed average fluxes is needed. 
Table 2 Overview of optimal hollow fibre module design for PDI modules

\begin{tabular}{|c|c|c|c|c|c|c|}
\hline $\begin{array}{l}\text { Filtration } \\
\text { Modes }\end{array}$ & Feed & Operating Details & $\begin{array}{l}\text { Module } \\
\text { Dimensions }\end{array}$ & $\begin{array}{l}\text { Variables } \\
\text { investigated }\end{array}$ & Main Findings & Ref \\
\hline Direct-flow & Inside & $\begin{array}{l}\text { - 2-D direct-flow channel and 3-D } \\
\text { filter pipe } \\
\text { - Fibre wall thickness ignored } \\
\text { - Not a real filtration unit } \\
\text { - Mathematical model investigated }\end{array}$ & $\begin{array}{c}\text { Dimensionless } \\
\text { quantities }\end{array}$ & $\begin{array}{ll}J_{a v,} & \mathrm{~L} \\
k_{m,} & \gamma\end{array}$ & $\begin{array}{l}\text { 1. Spatial variation in flux is minimised through } \\
\text { (1) low fluxes, (2) use of relatively low } k_{m} \text {, } \\
\text { and (3) spacing parameter close to unity. }\end{array}$ & {$[8]$} \\
\hline Direct-flow & Inside & $\begin{array}{l}\text { - DuPont B-9 module } \\
\text { - No backwash considered } \\
\text { - Pure water }\end{array}$ & $\begin{array}{c}a=0.021 \mathrm{~mm} \\
b=0.042 \mathrm{~mm} \\
L=765 \text { or } 311 \mathrm{~mm} \\
\varepsilon=0.45 \text { or } 0.51 \\
N_{\text {fibre }}=8.4 \times 10^{5} \text { or } \\
\quad 7.4 \times 10^{5}\end{array}$ & $L$ & $\begin{array}{l}\text { 1. Filtration productivity of hollow fibre } \\
\text { modules can be increased significantly } \\
\text { either by opening both fibre ends or by } \\
\text { fabricating shorter modules. }\end{array}$ & {$[12]$} \\
\hline Crossflow & $\begin{array}{l}\text { Inside: } \\
\text { 60-85 Lmh }\end{array}$ & $\begin{array}{l}\text { - Backflushing flow and } \\
\text { backflushing pressure studied } \\
\text { - Operated under constant flow or } \\
\text { constant pressure condition }\end{array}$ & $\begin{array}{l}a=0.3 \mathrm{~mm} \\
b=0.55 \mathrm{~mm} \\
L=0.6,1.2,1.8 \mathrm{~m}\end{array}$ & $L$ & $\begin{array}{l}\text { 1. An increase of the fibre length will result in a } \\
\text { corresponding increase of the flow or } \\
\text { pressure to achieve the same backwash } \\
\text { effect. } \\
\text { 2. The cleaning time should be extended for } \\
\text { longer fibres. }\end{array}$ & {$[15]$} \\
\hline Crossflow & $\begin{array}{l}\text { Inside: } \\
1.25 \times \\
10^{-5} \mathrm{~m}^{3} / \mathrm{s}\end{array}$ & $\begin{array}{l}\text { - Laboratory scale microfiltration } \\
\text { unit } \\
\text { - Constant module inlet flow rate } \\
\text { - Feed consists of a dilute solution } \\
\text { containing rigid spherical particles }\end{array}$ & $\begin{array}{l}a=0.1,0.29, \\
0.375 \mathrm{~mm} \\
L=0.305 \mathrm{~m}\end{array}$ & $a$ & $\begin{array}{l}\text { 1. The permeate flux (averaged over the } \\
\text { length) was found to vary by as much as } \\
65 \% \text { depending on the lumen radius. } \\
\text { 2. Both cake layer and membrane resistances } \\
\text { are similar in magnitude with an optimal } \\
\text { lumen radius that is dependent upon the } \\
\text { average permeate flux. }\end{array}$ & {$[21]$} \\
\hline
\end{tabular}

Note: Fibre inside radius $a$, fibre outside radius $b$, fibre length $L$, fibre permeance $k_{m}$, void fraction $\epsilon$, module packing density $\phi$, spacing parameter $\gamma$, imposed average flux $J_{a v}$ 
In this paper, the direct-flow filtration model will be analysed under typical industrial operating conditions to quantify the overall filtration performance by explicitly examining various geometric parameters, including inside fibre radius, $a$, wall thickness, $\Gamma$, void fraction, $\epsilon$, and fibre length, $L$, at various imposed average fluxes, $J_{a v}$. In contrast to previous work [8], this approach examines the transmembrane pressure difference (TMP) profiles established by the fluid mechanics in units with realistic industrially relevant dimensions.

Two performance parameters are defined and used as measures of merit. The normalised module productivity, $\beta$, is defined as:

$$
\beta=\frac{J_{a v}}{k_{m} P_{p}}(1-\epsilon),
$$

where $k_{m}$ is the permeance through the membrane walls, which is used as $300 \mathrm{Lmh} / \mathrm{bar}$ in this paper [5], $P_{p}$ is the pump driving (inlet) pressure (with respect to the ambient pressure as reference) observed during the filtration process, $J_{a v}$ is the imposed average flux, and $\epsilon$ is the void fraction.

$$
\frac{J_{a v}}{k_{m} P_{p}} \text { is a measure of the actual average flux to that which would }
$$
occur if all of the filtration were at the inlet pressure (assuming permeate side was uniformly at ambient pressure). $1-\epsilon$ is a measure of the area used for filtration to that theoretically available. The filtration uniformity factor, $\varphi$, used herein, is:

$$
\varphi=1-\frac{2}{L \dot{V}_{L}} \int_{0}^{L} \Delta \dot{V}(z) d z,
$$

where $\dot{V}_{L}=\int_{0}^{L} 2 \pi a J(z) d z$ is defined as the overall cumulative flowrate exiting at the capped end $\left(\dot{V}_{L}=\dot{Q}=2 \pi a L J_{a v}\right)$, and $\Delta \dot{V}(z)=\left|\dot{V}_{\text {ideal }}(z)-\dot{V}_{c}(z)\right|$ with $\dot{V}_{c}(z)=\int_{0}^{z} 2 \pi a J(z) d z$ which is the actual cumulative flowrate of permeate at axial position $z$ and $\dot{V}_{\text {ideal }}(z)=\frac{z \dot{V}_{L}}{L}$ is the cumulative flowrate of permeate at axial position $z$ that would be filtered through the membrane under strictly uniform (idealized) filtration conditions.

Additionally, the advanced Taguchi method will be introduced to explicitly indicate the relative contribution of each geometrical parameter on the filtration performance parameters, $\beta$ and $\varphi$. 


\section{Model development}

\subsection{Setup}

A HF membrane system includes bundles of small porous HFs packed into a shell module (shown in Fig. 4), which is similar in configuration to a shell and tube heat exchanger. The key difference in direct-flow filtration is that there is no outlet on the tube side and no inlet on the shell side in the PDI format. The opposite is true for PDO format.

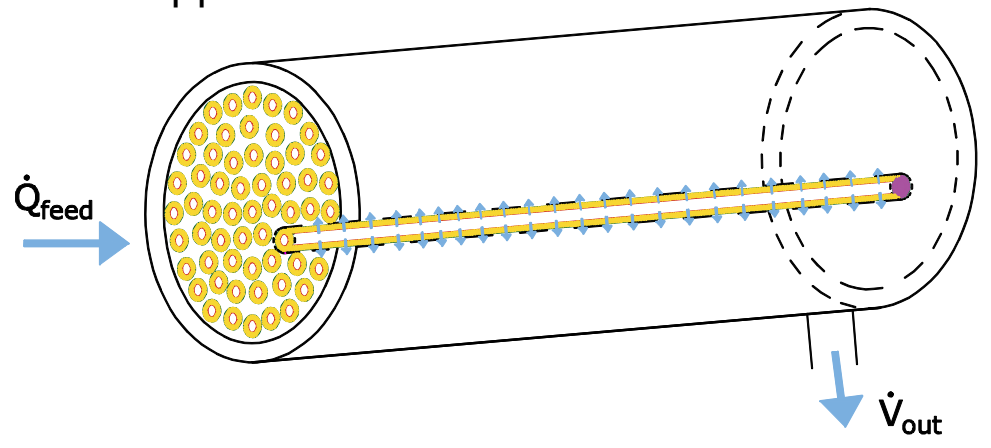

Fig. 4. Schematic of capped-ended hollow fibre membrane module. Please note the aspect ratio (length/fibre diameter) is not to scale.

The single fibre as highlighted in Fig. 4 is more closely examined in Fig. 5. The fibre has an internal radius $a$, an outer radius $b$ and a length $L$. For simplicity, a symmetry condition is applied so that a radial coordinate system $(r, z)$ can be used. In this axisymmetric coordinates, $r$ denotes the radial coordinate and $z$ represents the distance along the fibre length $L$. The yellow hashed annulus area represents the permeable wall of the fibre, with the inside fibre wall shown as the red circle and the outer fibre wall shown as the green circle. According to Happel [24] and Elmore and et.al [25], each single fibre can be envisioned as being bounded by an imaginary cylinder with zero-stress outer surface centred around the fibre. The assumption is known as the equivalent annulus approximation. This imaginary boundary is indicated with a dotted circle of radius $c$ in Fig. 5a. A constant permeate flow rate $\dot{Q}=2 \pi a L J_{a v}$ is applied to the model fibre based on the inside filtration area. For such an isolated fibre we consider the region inside the fibre as lumen side, the region outside as shell side. As shown in Fig. 5b, there is inside feed. The pressure in the lumen side is $p$, and in the shell side is $q$. However, the quantity of most interest is the transmembrane pressure difference $T M P, p-q$. The TMP profile directly indicates how the filtration process proceeds varies along the fibre length.

(a)

(b) 

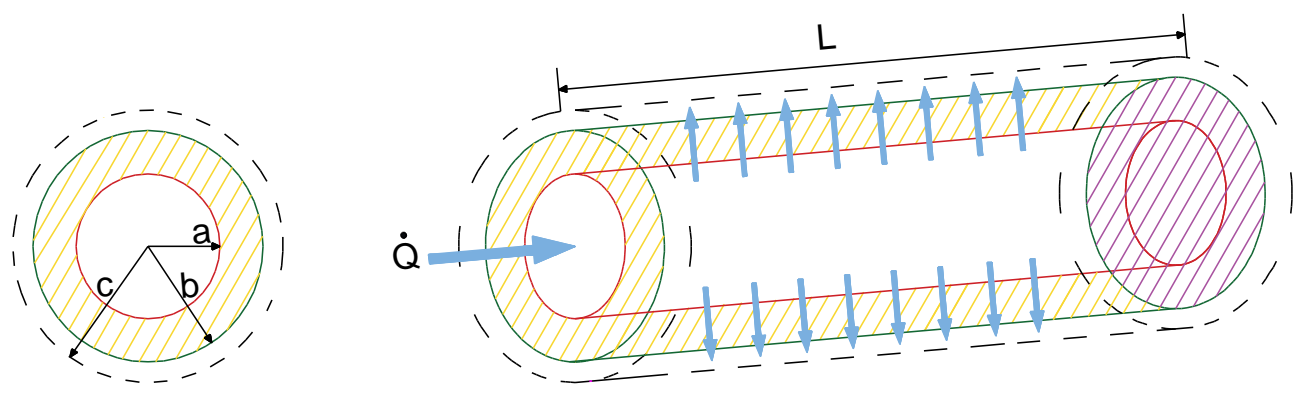

Fig. 5. Schematic of a single fibre as used in model development (a) cross sectional view; (b) overall side view with flow direction indicated. The aspect ratio (length/fibre diameter) is not to scale.

Industrial modules typically have a length of around $1.5 \mathrm{~m}$, the inside radius of the $\mathrm{HF}$ is around $0.4 \mathrm{~mm}$, therefore the aspect ratio (diameter/length) of the module $\delta=a / L \ll 1$. The fluid velocity in $r$ direction is $u$, and velocity along the fibre length direction is $w$. As explained in previous paper [8], the Reynolds number of our current model is reconsidered as $R e=(2 a \rho w) / \mu$, where $\rho$ is the density of the fluid (taken to be water), $w$ is the typical axial velocity where the average is used in Reynolds number calculation, and $\mu$ is the kinematic viscosity. With imposed average flux of $70 \mathrm{Lmh}$, the Reynolds number calculated with the above values of length and radius is 131, the reduced Reynolds number $\delta R e=O\left(10^{-2}\right) \ll 1$ [5]. Therefore, lubrication equations can be applied.

\subsection{Lubrication equations}

For the isolated fibre model, we consider the region inside the fibre as lumen side, the region outside as shell side. For lumen side (for $0 \leq r \leq$ $a$ and $0 \leq z \leq L)$, the lubrication equations can be written as

$$
\begin{aligned}
& \frac{1}{r} \frac{\partial}{\partial r}(r u)+\frac{\partial w}{\partial z}=0, \\
& \mu \frac{1}{r} \frac{\partial}{\partial r}\left(r \frac{\partial w}{\partial r}\right)=\frac{d p}{d z} .
\end{aligned}
$$

The boundary conditions for lumen side can be defined as

Symmetry:

No axial wall slip:

$$
\frac{\partial w}{\partial r}=u=0,
$$

$w=0$, when $r=0$,

when $r=a$, 


$$
\begin{array}{lll}
\text { Permeate flow: } & u=\frac{k(p-q)}{\mu a \ln \frac{b}{a}}, & \text { when } r=a, \\
\text { Fluid inflow: } & 2 \pi \int_{0}^{a} w r d r=\dot{Q}, & \text { when } z=0, \\
\text { No fluid outflow: } & w=0, & \text { when } z=L .
\end{array}
$$

Shell side region (for $b \leq r \leq c$ and $0 \leq z \leq L$ ) fluid also obeys the lubrication equations

$$
\begin{aligned}
& \frac{1}{r} \frac{\partial}{\partial r}(r u)+\frac{\partial w}{\partial z}=0, \\
& \mu \frac{1}{r} \frac{\partial}{\partial r}\left(r \frac{\partial w}{\partial r}\right)=\frac{d q}{d z} .
\end{aligned}
$$

The boundary conditions for shell side can be defined as

$$
\begin{array}{llr}
\text { Zero stress surface: } & \frac{\partial w}{\partial r}=u=0, & \text { when } r=c, \\
\text { No axial wall slip: } & w=0, & \text { when } r=b, \\
\text { Permeate flow: } & u=\frac{k(p-q)}{\mu b \ln \frac{b}{a}} & \text { when } r=b, \\
\text { No fluid inflow: } & w=0, & \text { when } z=0, \\
\text { Fixed outlet pressure: } & q=q_{L}=1 \mathrm{~atm} & \text { when } z=L .
\end{array}
$$

The equations can be solved analytically to get the transverse velocity expressions. For lumen side we find,

$$
\begin{gathered}
w=\frac{1}{4 \mu} \frac{d p}{d z}\left(r^{2}-a^{2}\right), \\
u=\frac{1}{16 \mu} \frac{d^{2} p}{d z^{2}}\left(2 a^{2} r-r^{3}\right),
\end{gathered}
$$

while on shell side,

$$
w=\frac{1}{4 \mu} \frac{d q}{d z}\left(r^{2}-2 c^{2} \ln \frac{r}{b}-b^{2}\right),
$$




$$
u=\frac{1}{16 \mu} \frac{d^{2} q}{d z^{2}}\left\{2 b^{2} r-r^{3}+c^{2}\left[-2 r+4 r \ln \frac{r}{b}-\frac{2 b^{2}}{r}+c^{2}\left(\frac{3}{r}-\frac{4}{r} \ln \frac{c}{b}\right)\right]\right\}
$$

Substituting the boundary equations into the velocity expressions, a system of ODEs can be found:

$$
\begin{array}{clrl}
\frac{d^{2} p}{d z^{2}}=\frac{16 k(p-q)}{\Lambda_{1}}, & \left.\frac{d p}{d z}\right|_{z=0}=-\frac{8 \mu \dot{Q}}{\pi a^{4}}, & \left.\frac{d p}{d z}\right|_{z=L}=0, \\
\frac{d^{2} q}{d z^{2}}=-\frac{16 k(p-q)}{\Lambda_{2}}, & \left.\frac{d q}{d z}\right|_{z=0}=0, & \left.q\right|_{z=L}=q_{L} \\
=1 \mathrm{~atm}, &
\end{array}
$$

where

$$
\begin{gathered}
\Lambda_{1}=a^{4} \ln \frac{b}{a}, \\
\Lambda_{2}=-b^{4} \ln \frac{b}{a}+c^{2} \ln \frac{b}{a}\left[4 b^{2}-c^{2}\left(3-4 \ln \frac{c}{b}\right)\right], \\
\Lambda_{3}=-\frac{8 \mu \dot{Q}}{\pi a^{4}} .
\end{gathered}
$$

The ODEs can be solved analytically to obtain expressions for the pressures:

$$
\begin{gathered}
p(z)=\frac{1}{\Lambda_{1}+\Lambda_{2}}\left[\Lambda_{2} \mathcal{N}(z)-\Lambda_{1} \Lambda_{3}(L-z)+\mathcal{N}_{0}\right]+q_{L}, \\
q(z)=\frac{1}{\Lambda_{1}+\Lambda_{2}}\left[-\Lambda_{1} \mathcal{N}(z)-\Lambda_{1} \Lambda_{3}(L-z)+\mathcal{N}_{0}\right]+q_{L},
\end{gathered}
$$

where

$$
\mathcal{N}(z)=\mathrm{TMP}=-\frac{\Lambda_{3}}{C_{1}} \operatorname{Csch}\left(C_{1} L\right)\left[\frac{\Lambda_{1}}{\Lambda_{2}} \operatorname{Cosh}\left(C_{1} z\right)+\operatorname{Cosh}\left[C_{1}(L-z)\right],\right.
$$




$$
\begin{gathered}
\mathcal{N}_{0}=-\frac{\Lambda_{1} \Lambda_{3}}{C_{1}}\left[\frac{\Lambda_{1}}{\Lambda_{2}} \operatorname{Coth}\left(C_{1} L\right)+\operatorname{Csch}\left(C_{1} L\right)\right], \\
C_{1}=\sqrt{16 k\left(\frac{1}{\Lambda_{1}}+\frac{1}{\Lambda_{2}}\right)} .
\end{gathered}
$$

From Darcy's law, the relationship between the membrane permeance $k_{m}$, the membrane permeability $k$ (based on inner fibre area) and the membrane resistance $R_{m}$, are defined respectively ( $J$ denotes for the local flux across the membrane, in our calculation we used the imposed average flux $J_{a v}$ )

$$
\begin{gathered}
k_{m}=\frac{J}{\mathrm{TMP}}, \\
J=\frac{\mathrm{TMP}}{\mu R_{m}}, \\
k=\frac{a}{R_{m}} \ln \left(\frac{b}{a}\right) .
\end{gathered}
$$

\section{Results and discussion}

Before displaying results indicating the influence of void fraction, fibre diameters and other parameters an overview of the pressure profiles is given using the parameter $\gamma$ with parallel that used in [8] where:

$$
\gamma=\frac{\text { area in the shell side }}{\text { area in the lumen side }}=\frac{\pi c^{2}-\pi b^{2}}{\pi a^{2}}=\frac{c^{2}-b^{2}}{a^{2}} .
$$

\subsection{Influence of fibre spacing on axial pressure profiles}

Fig. 6 shows three patterns of pressure profiles. When the spacing on the shell side is large as in Fig. 6c the shell side behaves as a quiescent bath that is essentially at the exit pressure over the whole length. With equal areas on the two sides (Fig. 6b) the difference of $p-q$ (i.e. TMP) varies modestly along the fibre length. Too smaller a value of $\gamma$ (Fig. 6a) introduces a hydrodynamic resistance on the shell side and this results in a major maldistribution of TMP and hence of fluxes. 

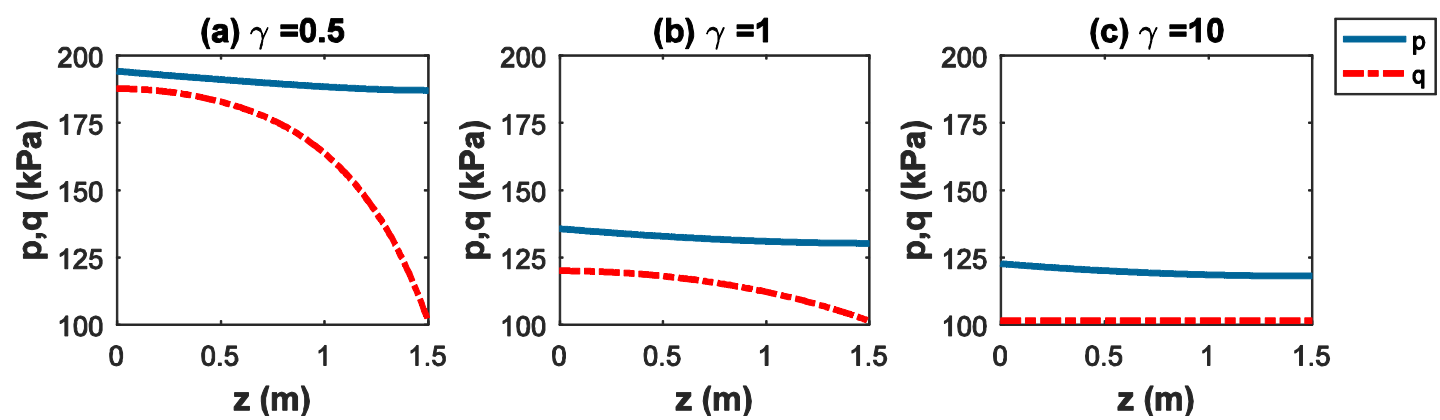

Fig. 6. Variation of fluid pressure in the lumen side, $\mathrm{p}$, and in the shell side, $\mathrm{q}$ given by equation (24, 25). Fixed parameters: $a=0.4 \mathrm{~mm}, \Gamma=0.25 \mathrm{~mm}, L=1.5 \mathrm{~m}, J_{a v}=70 \mathrm{Lmh}$ and $k_{m}=300 \mathrm{Lmh} /$ bar with spacing parameters (a) $\gamma=0.5$, (b) $\gamma=1$ and (c) $\gamma=10$.

As shown in Fig. 7, with a small module spacing parameter $\gamma=0.5$, TMP increases along the fibre length and there is a large variation between minimum and maximum values. For $\gamma$ between 1 and 3 , the TMP profiles indicate relative uniform distribution but one should note that the local flux at $z=0$ becomes higher than that at the capped end when $\gamma>2$. However, continuing to increase $\gamma$ value beyond approximately 3 has only a small influence on the TMP plots and the overall filtration process (purple line and green line overlap completely as shown in Fig. 7). This is in agreement with a previous conclusion made [8] without considering wall thickness.

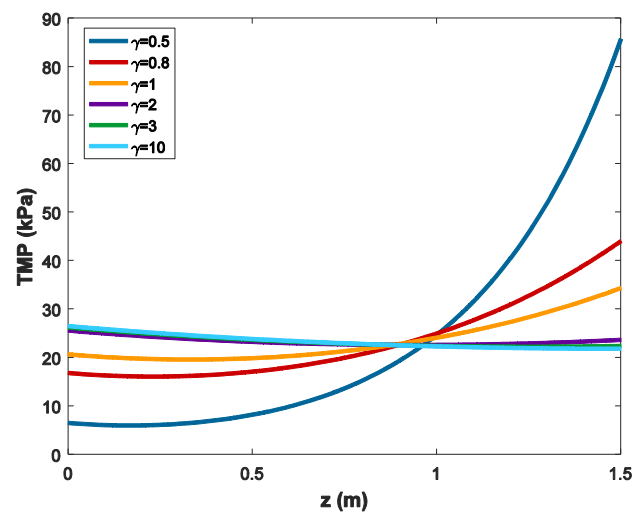

Fig. 7. The effect of spacing parameter, $\gamma$, upon the transmembrane pressure difference (TMP) profiles versus axial distance, $z$ at different spacing parameter $\gamma$. Fixed parameters: $a=0.4 \mathrm{~mm}, \Gamma=0.25 \mathrm{~mm}, L=1.5 \mathrm{~m}, J_{a v}=70 \mathrm{Lmh}$ and $k_{m}=300 \mathrm{Lmh} / \mathrm{bar}$.

In previous dimensionless model [8], the equivalent dimensionless variable of permeance, $k_{m}$, was set from 0.1 to 10 . For fixed parameters $a=0.4 \mathrm{~mm}, \Gamma=0.25 \mathrm{~mm}, L=1.5 \mathrm{~m}$ and $J_{a v}=70 \mathrm{Lmh}$, a value of 1 implies a permeance of $11500 \mathrm{Lmh} / \mathrm{bar}$, while a value of 0.1 equates $1150 \mathrm{Lmh} / \mathrm{bar}$ which is still higher by a factor of 3.83 , than $300 \mathrm{Lmh} / \mathrm{bar}$ found in 
commercial operations. The permeance $\mathrm{k}_{\mathrm{m}}=300 \mathrm{Lmh} / \mathrm{bar}$ used in this paper is equivalent to the dimensionless variable of 0.026 in the previous study which is outside of the range considered [8]. Hence, the representative dimensionless value used in previous work is not applicable in real water industry. The authors did note that lower permeance has the effect of creating better uniformity and this is illustrated in Fig. 8. The extreme non-uniformity noted previously can now be unambiguously attributed to the permeance values chosen. For typical industrial values of the parameters (Fig. 8) a permeance of $300 \mathrm{Lmh} /$ bar gives only modest spatial variation if $\gamma \gg 0.8$.

(a) $k_{m}=300 ~ L m h / b a r ~\left(k_{d}=0.026\right)$

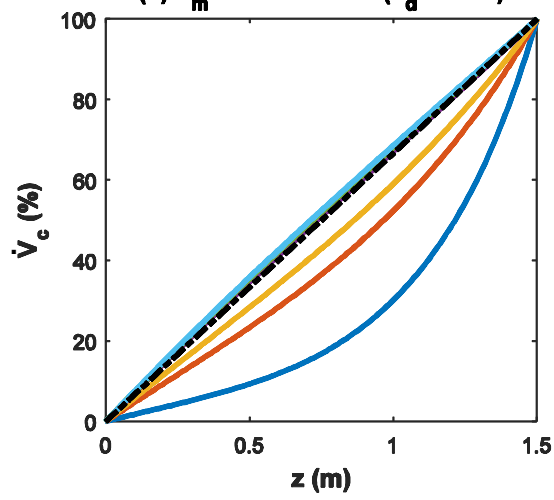

(c) $k_{m}=11500 \mathrm{Lmh} / \mathrm{bar}\left(k_{d}=1\right)$

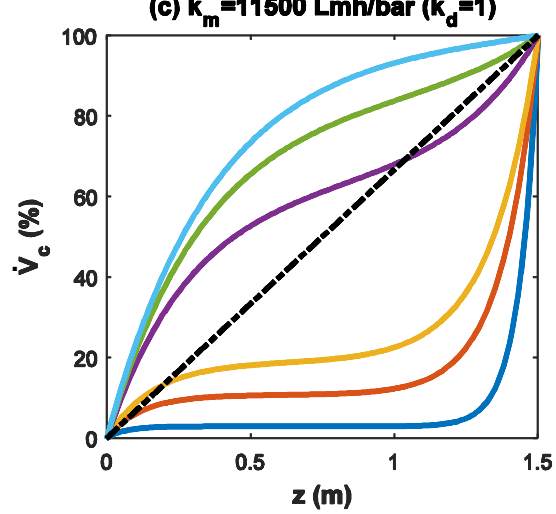

(b) $k_{m}=1150 L \mathrm{mh} / \mathrm{bar}\left(k_{d}=0.1\right)$

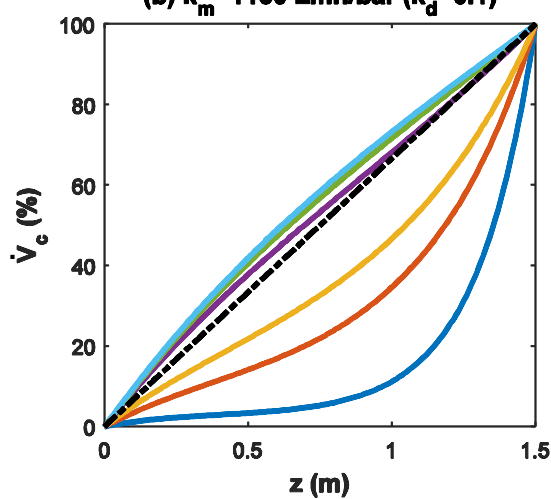

(d) $k_{m}=115000 \mathrm{Lmh} / \mathrm{bar}\left(k_{d}=10\right)$

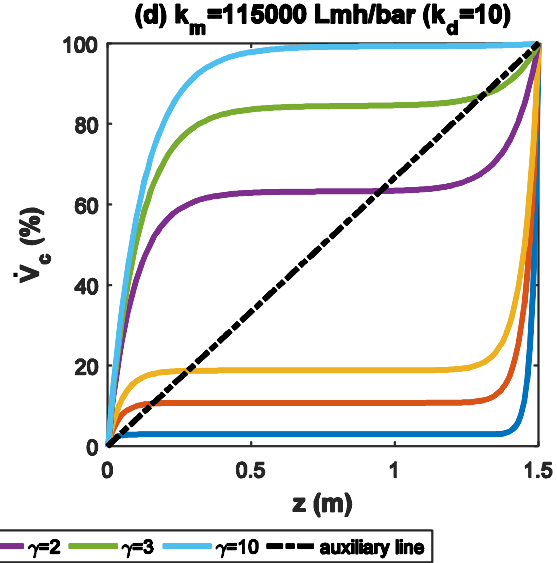

Fig. 8 The effect of spacing parameter, $\gamma$, upon the cumulative volume transported through the fibre walls, $\dot{V}_{c}(\%)$, versus axial distance, $z$. Fixed parameters: $a=0.4 \mathrm{~mm}$, $\Gamma=0.25 \mathrm{~mm}, L=1.5 \mathrm{~m}$, and $J_{a v}=70 \mathrm{Lmh}$ with permeances (a) $k_{m}=300 \mathrm{Lmh} / \mathrm{bar}$, (b) $k_{m}=$ $1150 \mathrm{Lmh} /$ bar (c) $k_{m}=11500 \mathrm{Lmh} /$ bar and (d) $k_{m}=115000 \mathrm{Lmh} /$ bar. $^{3}$

${ }^{3}$ Permeance, $k_{m}$, is transferred to equivalent value of dimensionless variable $k_{d}$, which is defined as dimensionless permeability in pervious study [7]. 


\subsection{Selection of Design parameters}

In real membrane manufacturing the module spacing parameter, $\gamma$, cannot be adjusted directly, instead, a hollow-fibre module is usually designed with regard to void fraction, $\epsilon$, which is defined as

$$
\epsilon=\frac{\text { free area in the shell side }}{\text { total area }}=\frac{\pi c^{2}-\pi b^{2}}{\pi c^{2}}=\frac{c^{2}-b^{2}}{c^{2}} .
$$

The lowest achievable void fraction for square array is $\epsilon=0.215$ while for equilateral triangular array is $\epsilon=0.093$. In order to alter the overall void fraction, $\epsilon$, fibre properties including inside fibre radius, $a$, wall thickness, $\Gamma$, and fibre length, $L$, are therefore to be examined. Typically, the fibre wall thickness is designed as two thirds of the fibre inner radius to maintain the mechanical strength [5]. Thus, the effect of fibre wall thickness upon the filtration behaviour is not emphasised in this paper. A typical commercial value of $\Gamma=0.25 \mathrm{~mm}$ is used. Permeance, $k_{m}$, is not investigated further in this paper, as permeability, $k$, is based on an industrial value for a clean membrane. This paper seeks explicitly to examine the filtration behaviour based on the effect of geometric factors and fluid inflow. Thus the variables considered are: module void fraction, $\epsilon$, inside fibre radius, $a$, fibre length, $L$, and imposed average fluxes, $J_{a v}$.

\subsubsection{Influence of void fraction}

In Fig. 9a, TMP profiles are compared at different void fraction, $\epsilon$, with other parameters set at: inner radius $a=0.4 \mathrm{~mm}$, wall thickness $\Gamma=$ $0.25 \mathrm{~mm}$, fibre length $L=1.5 \mathrm{~m}$, imposed average flux $J_{a v}=70 \mathrm{Lmh}$ and permeance $k_{m}=300 \mathrm{Lmh} / \mathrm{bar}$. These are the values for the standard case. The profiles for $a=0.15,0.2$ and $0.25 \mathrm{~mm}$ are not fully shown in Fig. 9a so as not to compress other details. At small $\epsilon$ values, the fluid hardly go through the permeate wall near the entrance and thus the majority of the filtration process takes place near the capped end. When $\epsilon=0.25$ (yellow line), a rapid increase of TMP is observed near the capped end, which results in the local flux at capped end is over twice that at the entrance. This can be even worse for much smaller $\epsilon$ values (i.e. dark blue line $\epsilon=0.15$ ) as indicated in the cumulative fluid volume plots (Fig. 9b). At $\epsilon=0.15,80 \%$ of the fluid passes through the membrane over the last $20 \%$ fibre length. 


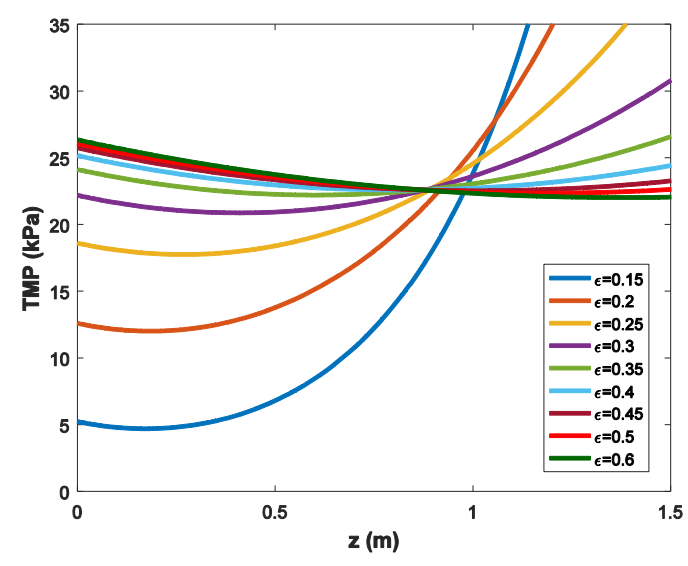

(a)

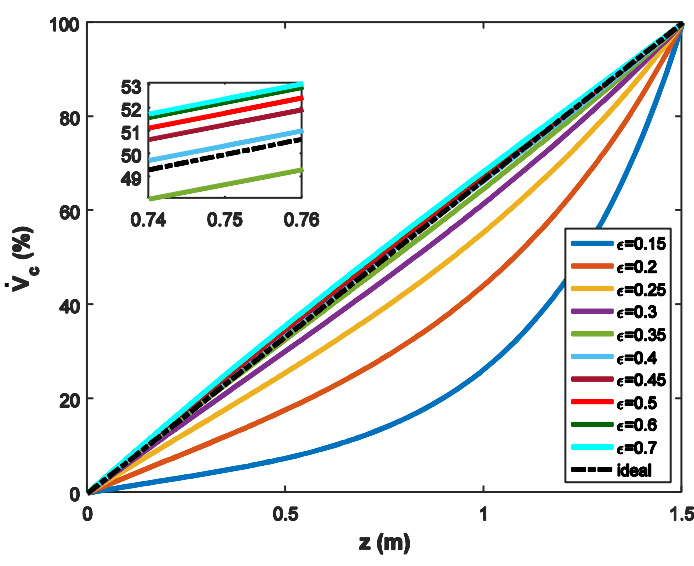

(b)

Fig. 9. The effect of void fraction, $\epsilon$, upon (a) the transmembrane pressure difference (TMP) profiles and (b) the cumulative volume transported through the fibre walls, $\dot{V}_{c}(\%)$, versus axial distance, $z$. Fixed parameters: $a=0.4 \mathrm{~mm}, \Gamma=0.25 \mathrm{~mm}, L=1.5 \mathrm{~m}, J_{a v}=70 \mathrm{Lmh}$ and $k_{m}=300 \mathrm{Lmh} / \mathrm{bar}$.

In practice the maximum pressure tolerance to avoid permeability loss due to active layer compression or fibre damage is $140 \mathrm{kPa}$ to $300 \mathrm{kPa}$, and the maximum TMP to ensure stable low fouling operation is $70 \mathrm{kPa}$ [5]. A value of $\epsilon=0.15$ is impractical as it would involve a maximum lumen side pressure of circa $210 \mathrm{kPa}$ and a corresponding maximum TMP of $95 \mathrm{kPa}$. Increasing $\epsilon$ promotes uniform filtration, but increasing $\epsilon$ beyond approximately 0.5 will hardly change the cumulative volume curves (Fig. $9 b)$. As such increase will reduce the filtration area the module productivity will reduce. This matter and the trade-off between uniformity and productivity is discussed later in section 3.3.

\subsubsection{Influence of fibre inner radius and wall thickness}

Fig. 10a shows TMP profiles for different inner radii, $a$, with other parameters fixed. All TMP profiles show negative gradient with increasing axial distance and minima around $1 \mathrm{~m}$ fibre length. The axial variation of TMP is greater for small $a$; the range of $a$ encompasses the industrial range of 0.4 to $0.45 \mathrm{~mm}$. When $a=0.35 \mathrm{~mm}$, a maximum TMP of $27.1 \mathrm{kPa}$ is found at $z=0$ and a minimum TMP of $22.1 \mathrm{kPa}$ is found at $z=1.08 \mathrm{~m}$ (A greater variation is found for smaller $\epsilon$ ). The filtration process in Fig. 10b show more non-uniform distribution at small $a$ values, increasing $a$ values can minimize the differences of the maximum and minimum TMP values thus promotes a more uniform filtration. Kim et al. [13] reached a similar conclusion and recommended a fibre of larger inner diameter and small wall thickness as long as it were of sufficient mechanical strength. 


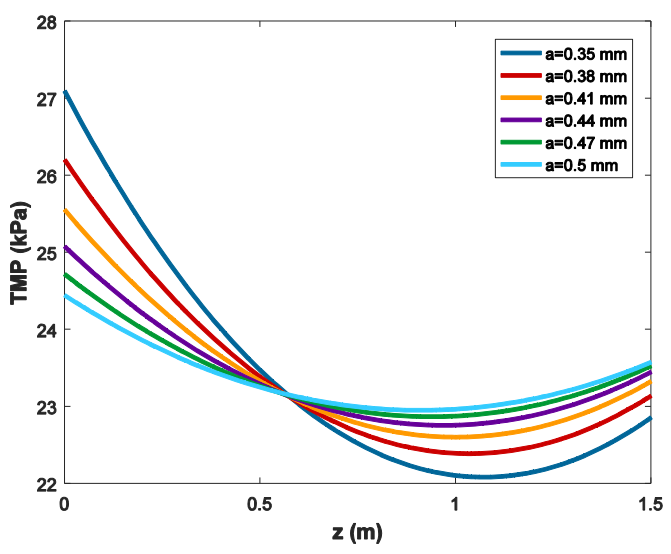

(a)

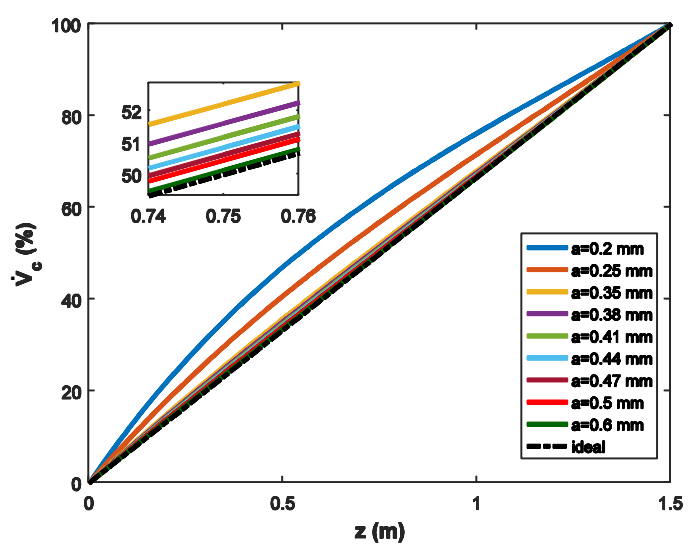

(b)

Fig. 10. The effect of inner radius, $a$, upon (a) the transmembrane pressure difference (TMP) profiles and (b) the cumulative volume transported through the fibre walls, $\dot{V}_{c}(\%)$, versus axial distance, $z$. Fixed parameters: $\epsilon=0.45, \Gamma=0.25 \mathrm{~mm}, L=1.5 \mathrm{~m}, J_{a v}=70 \mathrm{Lmh}$ and $k_{m}=300 \mathrm{Lmh} / \mathrm{bar}$.

Although not shown graphically our study also indicates that a thinner fibre wall promotes uniform distribution of local flux. However, the wall thickness variations show less impact on the overall filtration process than other parameters. Therefore, the effect of fibre wall thickness is not emphasised in this paper. In commercial products, although a very thin fibre wall can ensure more uniform distribution of the filtration behaviour, it is always avoided because it lowers the mechanical strength as the Young's modulus decreases with wall thickness [26]. In practice, the fibre wall thickness is usually two thirds of the fibre inner radius.

\subsubsection{Influence of fibre length}

Fig. 11a shows TMP profiles for various fibre length, $L$, with other parameters fixed. The concave curves with a minimum around $67 \%$ of the length of the fibre show a similar pattern to that given above for the effect of fibre radius on TMP profiles as seen in Fig. 10, the longer the fibre the greater the TMP variation. The TMP variation of $5.9 \mathrm{kPa}$ at $L=2.4 \mathrm{~m}$ is over triple that of $1.6 \mathrm{kPa}$ for $L=1.2 \mathrm{~m}$. A shorter fibre is preferred but module productivity will be reduced which is a trade-off discussed more fully later in section 3.3. 


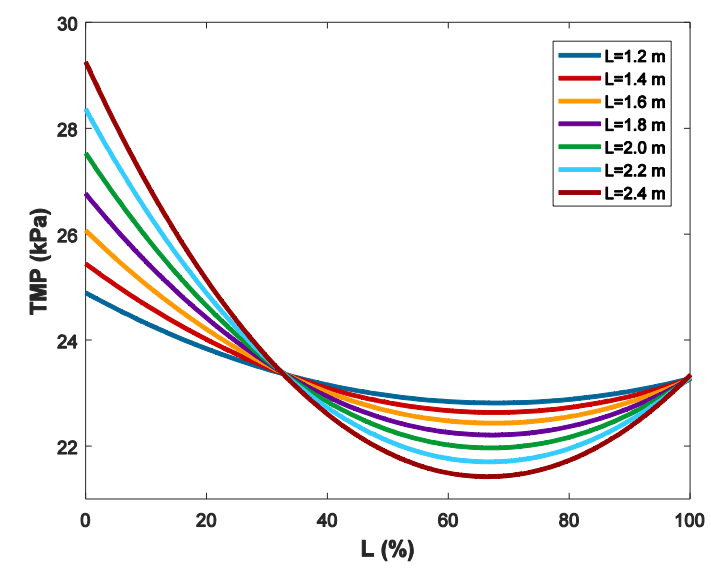

(a)

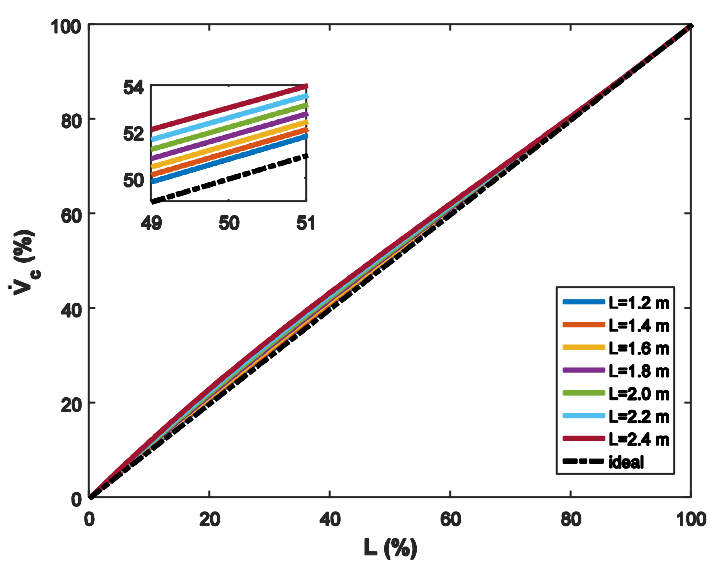

(b)

Fig. 11. The effect of fibre length, $L$, upon (a) the transmembrane pressure difference (TMP) profiles and (b) the cumulative volume transported through the fibre walls, $\dot{V}_{c}(\%)$, versus percentage of the fibre length at different fibre length, $L(\%)$. Fixed parameters: $a=0.4 \mathrm{~mm}, \Gamma=0.25 \mathrm{~mm}, \epsilon=0.45, J_{a v}=70 \mathrm{Lmh}$ and $k_{m}=300 \mathrm{Lmh} / \mathrm{bar}$.

The effect of fibre length on TMP profiles at various inner radii and module void fractions are compared in Fig. 12. The plots revel that increasing inner radius can minimise the maximum and minimum TMPs. The effect of changes in the module void fraction are small if the fibre length is $L=1.2 \mathrm{~m}$. For longer fibres increasing $\epsilon$ increases the TMP at the inlet. Now as the average flux and permeance are fixed the average TMP is the same for every case covered in Fig. 12, so modules with higher TMPs at inlet will also have lower TMPs elsewhere along the module i.e. the variation in TMP increases. Although Fig. $11 \mathrm{a}$ and Fig. 12 seem to suggest unique crossover points at particular values of $\%$ length it is found on close examination that they are spread over a small range, e.g. from around $26.5 \%$ to $28 \%$ and $87 \%$ to $89 \%$ in Fig. 12 a or even a tighter spread of just $0.3 \%$ (36.0 to $36.3 \%)$ in Fig. 12f. We seek to explain this observation. Firstly consider two curves one with a high inlet TMP and one with a lower inlet TMP. Clearly the former will former more of a ' $U$ ' and the latter will be flatter. These curves will have two crossover points. Now add an intermediate curve and consider it with respect to the original two curves. For each pairing there will be two crossover points but there is no particular reason why these would be unique values and upon closer inspection they are not unique values. 

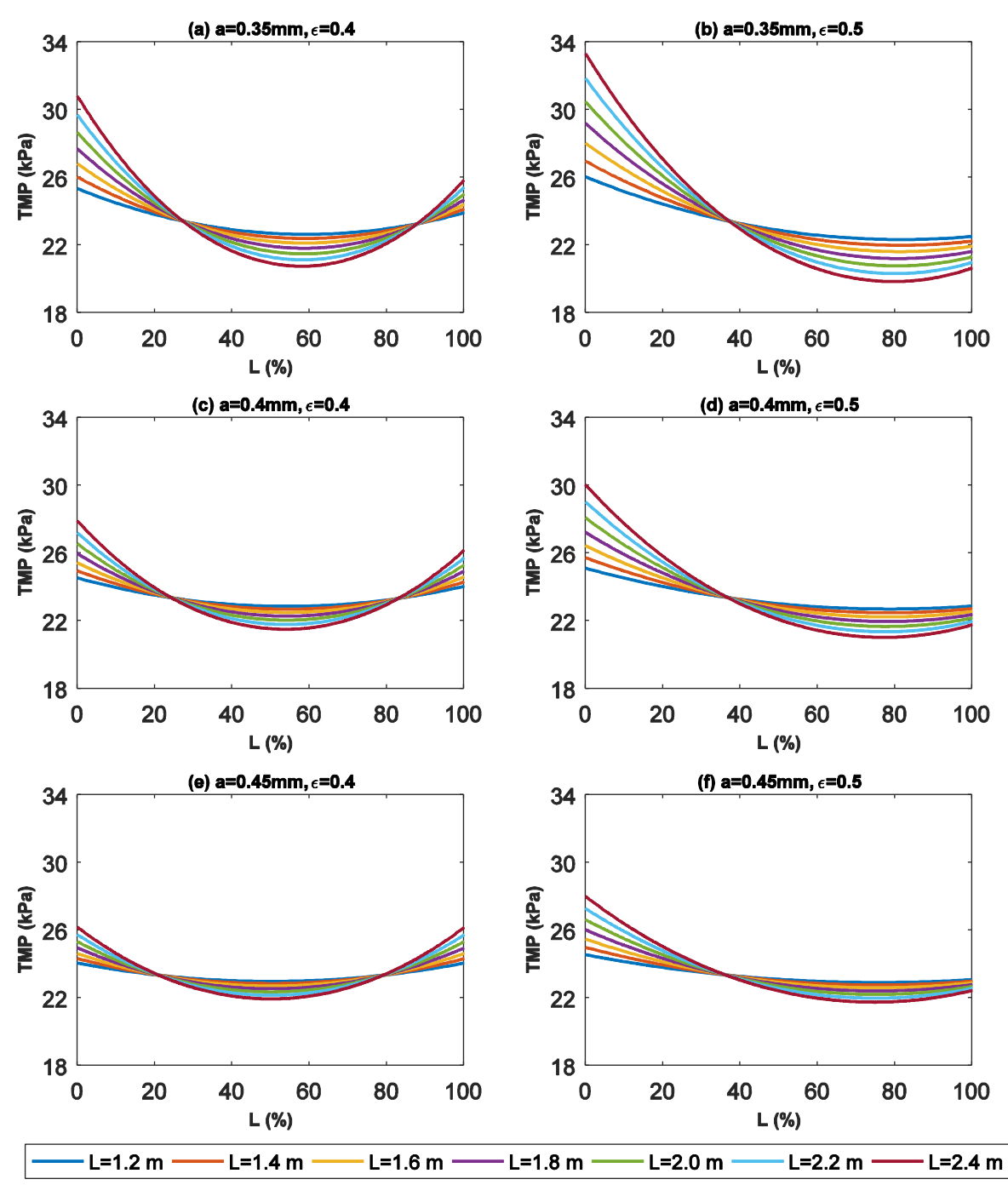

Fig. 12. The effect of fibre length, $L$, upon the transmembrane pressure difference (TMP) profiles versus percentage of the fibre length at different fibre length, $L(\%)$. Fixed parameters: $\Gamma=0.25 \mathrm{~mm}, J_{a v}=70 \mathrm{Lmh}$ and $k_{m}=300 \mathrm{Lmh} / \mathrm{bar}$. (a) $a=0.35 \mathrm{~mm}, \epsilon=0.4$, (b) $a=0.35 \mathrm{~mm}, \epsilon=0.5$, (c) $a=0.4 \mathrm{~mm}, \epsilon=0.4$, (d) $a=0.4 \mathrm{~mm}, \epsilon=0.5$, (e) $a=0.45 \mathrm{~mm}, \epsilon=0.4$, (f) $a=0.45 \mathrm{~mm}, \epsilon=0.5$.

\subsubsection{Influence of imposed average flux}

In Fig. 13, surface plots of TMP profiles at different imposed average flux, $J_{a v}$, (based on the inside fibre area $2 \pi a L$ ) are investigated at various fibre lengths, with other parameters fixed as given in caption. Unlike previous figures the standard parameters in Fig. 13 are $a=0.3 \mathrm{~mm}$, $\epsilon=0.35$, and $L=1.6 \mathrm{~m}$ except when specifically varied. The first three subplots examine the effect of changing $L$, the middle set the effect of $a$, and the last set the effect of $\epsilon$. Negative gradient of the TMP profiles are observed for the first two-thirds of the fibre length. After a minimum 
value around this point TMPs then slightly increase uptil the end of the fibre.

Generally, a higher imposed average flux is expected as it will effectively increase the local flux along the fibre length thus more output can be achieved through the filtration process. However, very high imposed average flux applied on the membrane walls will cause fouling issues. As Field et al. [10, 27] pointed too high a starting flux will lead to over-fouling. Although fouling cannot be avoided in practice, a relatively lower flow can restrain particles build-up on the membrane surface. Furthermore with a highly compressible layer a higher driving force (provided by increasing TMP) can be largely offset by the increased resistance resulting from a compressible layer.

As shown in Figure 13 very long fibres lead to significantly more curvature in the TMP profiles. Thus the flux distribution will be uneven and at the capped end there will be a coupling of a relative high solids loading with a relatively high local flux and this will lead to locally high fouling. Initially for a few cycles this will not be problematic but it is not efficient in the long term. Other plots show that relatively small inner fibre radius and relatively small void fraction also lead to greater curvature especially at higher fluxes. 

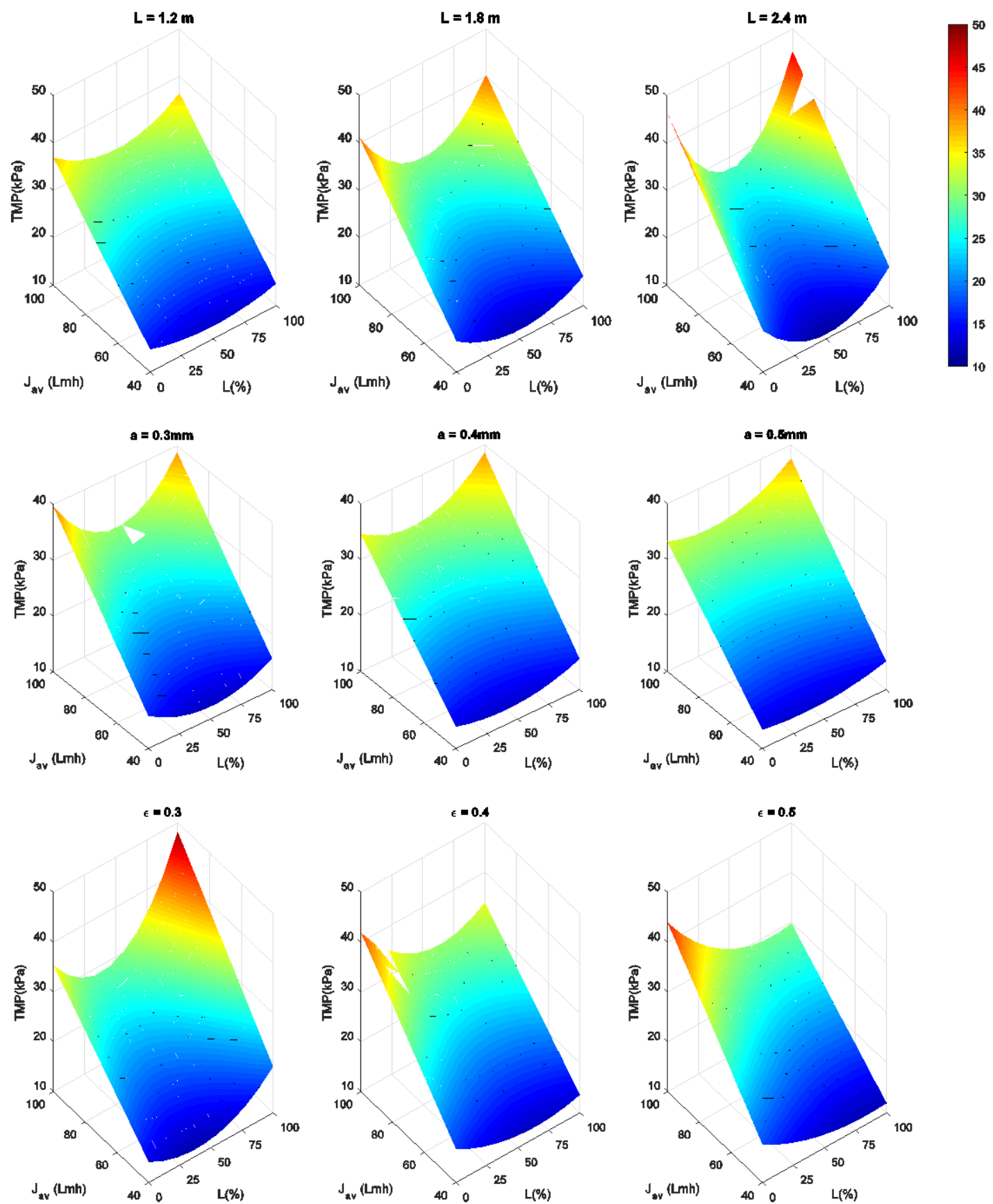

Fig. 13. The effect of imposed average flux, $J_{a v}$, upon the transmembrane pressure difference (TMP) profiles versus percentage of the fibre length at different fibre length, $L(\%)$.Except where indicated standard parameters were as follows: $a=0.3 \mathrm{~mm}, \epsilon=0.35$, $\Gamma=0.25 \mathrm{~mm}, L=1.6 \mathrm{~m}$ and $k_{m}=300 \mathrm{Lmh} /$ bar. 


\subsection{Filtration performance}

We have so far considered the effects of several design parameters on the TMP profiles and the fluid filtration distribution. However, the overall filtration performance should be quantified both in terms of its productivity and uniformity. The latter is taken to be a proxy for an ability to curtail fouling effects. Thus performance parameters of the normalized module productivity, $\beta$, and the filtration uniformity factor, $\varphi$, are presented together in Fig. 14.
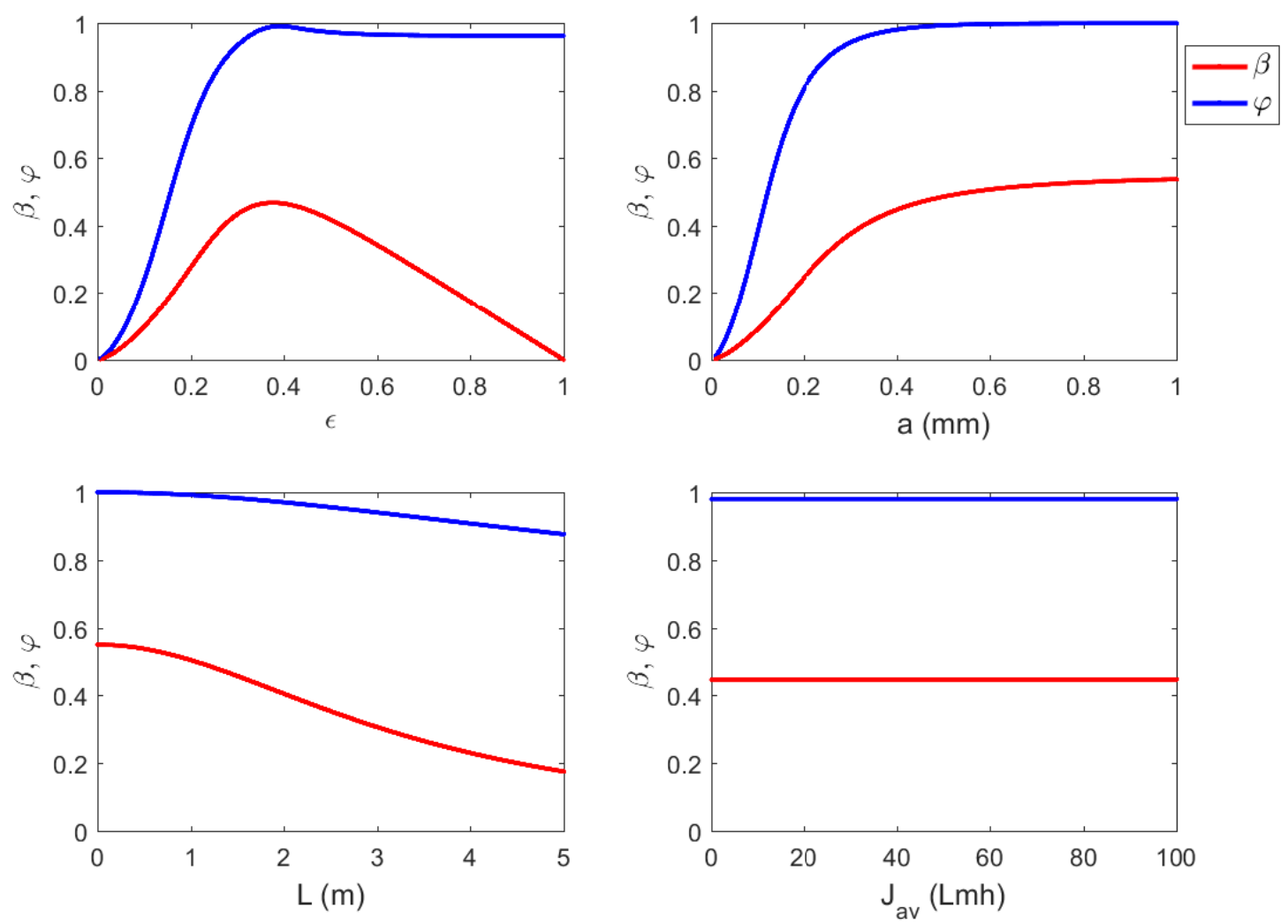

Fig. 14. The normalized module productivity, $\beta$, and the uniformity of the filtration behaviour, $\varphi$, of the filtration process versus the design control parameters. (a) void fraction, $\epsilon$, (b) inner radius, $a$, (c) fibre length, $L$, and (d) imposed average flux, $J_{a v}$, respectively. Standard parameters: $a=0.4 \mathrm{~mm}, \epsilon=0.45, \Gamma=0.25 \mathrm{~mm}, L=1.6 \mathrm{~m}, J_{a v}=70 \mathrm{Lmh}$ and $k_{m}=300 \mathrm{Lmh} / \mathrm{bar}$.

In Fig. 14, the normalized module productivity factor, $\beta$, is shown plotted against each design parameters. An optimum range around 0.2 to 0.45 of void fraction is suggested in Fig. 14a. Further increases reduce the overall module productivity. In Fig. $14 \mathrm{~b}$, below $0.5, \beta$ is proportional to the inside fibre radius which validates the suggestion that the larger the inner radius the more uniform of the filtration process will be achieved (as shown in Fig. 10), however further beyond 0.5 the overall filtration 
productivity will not change. In Fig. 14d, higher imposed average flux effectively increase the local flux along the fibre length thus more output can be achieved through the filtration process.

In Fig. 14, the filtration uniformity factor, $\varphi$, is plotted against each design parameter. As discussed before, higher $\varphi$ values indicate more uniform distribution of the local flux, the idealised universal uniform would be $\varphi=1$. In Fig. 14a and $\mathrm{b}$ increasing the void fraction and the inside fibre radius the overall filtration process will lead to more uniformity (as seen also in Fig. 9b and Fig. 10b). In Fig. 14c, the uniformity of the overall filtration process will weaken as the fibre length increases, as seen in Fig. $11 \mathrm{~b}$ previously. In Fig. 14d, the uniformity of the filtration is shown as being independent of the imposed average flux. The adverse effect of high fluxes and thus higher throughput will become apparent when nonuniformity of fibre spacing is taken into account and allowance is made for the pressure losses associated with exit flows. Table 3 provides an overall summary and clearly shows that our model can be validated against industrial practice that has evolved over the last 20 years. Industrial practice has been detailed elsewhere (Table A1 of [5]) and the commercial ranges given in Table 3 are based mainly on this source.

For void fraction our modelling suggests a range of 0.35 to 0.45 and industrial practice is $0.4-0.45$. For inner radius our modelling suggests that the value should be $>0.4 \mathrm{~mm}$ and naturally one would not design for this to be larger than necessary as there is a desire to have as much surface area per unit volume as practicable. Thus we suggest close to $0.4 \mathrm{~mm}$ and industrial practice is $0.4-0.45 \mathrm{~mm}$. For fibre length our modelling suggests that the value should be $<1.8 \mathrm{~m}$ and because potting is relatively expensive one would not design for this to be much shorter; industrial practice is $1.5-1.8 \mathrm{~m}$.

Table 3 Summary table of modelling results

\begin{tabular}{lccccc}
$\begin{array}{l}\text { Design } \\
\text { parameters }\end{array}$ & Void fraction & $\begin{array}{l}\text { Inner } \\
\text { radius } \\
\mathbf{( m m )}\end{array}$ & $\begin{array}{l}\text { Wall } \\
\text { thickness } \\
\mathbf{( m m )}\end{array}$ & $\begin{array}{l}\text { Fibre } \\
\text { length } \\
\mathbf{( m )}\end{array}$ & $\begin{array}{l}\text { Imposed } \\
\text { average flux } \\
\text { (Lmh) }\end{array}$ \\
\hline Productivity & $0.3 \leq \epsilon \leq 0.45$ & $a \geq 0.35$ & $\Gamma \uparrow$ & $L \leq 2$ & $\begin{array}{c}\text { No obvious } \\
\text { effect }\end{array}$ \\
\hline Uniformity & $0.35 \leq \epsilon \leq 0.45$ & $a \geq 0.4$ & $0.15 \leq \Gamma \leq 0.3$ & $L \leq 1.8$ & $\begin{array}{c}\text { No obvious } \\
\text { effect }\end{array}$ \\
\hline $\begin{array}{l}\text { Commercial } \\
\text { ranges [5] }\end{array}$ & $0.4 \leq \epsilon \leq 0.45$ & $0.4 \leq a \leq 0.45$ & $\Gamma \approx \frac{2}{3} a$ & $1.5 \leq L \leq 1.8$ & $60 \leq J_{a v} \leq 80$ \\
\hline $\begin{array}{l}\text { Other } \\
\text { concerns }\end{array}$ & $\begin{array}{c}\text { Overall } \\
\text { module size }\end{array}$ & $\begin{array}{c}\text { Mechanical } \\
\text { strength }\end{array}$ & $\begin{array}{c}\text { Mechanical } \\
\text { strength }\end{array}$ & $\begin{array}{c}\text { Overall } \\
\text { module size }\end{array}$ & $\begin{array}{c}\text { Membrane } \\
\text { fouling }\end{array}$ \\
\hline
\end{tabular}




\subsection{Taguchi method}

To combine the total influence of four control parameters on the overall module productivity and the uniformity distribution of the local flux, the multiple linear regression equations of $\beta$ and $\varphi$ developed from the Taguchi method [28] are shown as follows

$$
\begin{aligned}
& \beta=0.52287 a-0.46973 \epsilon-0.09169 L-0.00010 J_{a v}+0.59117, \\
& \varphi=0.21615 a-0.12675 \epsilon-0.01548 L-0.00003 J_{a v}+0.96884,
\end{aligned}
$$

where $a, \epsilon, L$, and $J_{a v}$ are the inside fibre radius, fibre wall thickness, module void fraction, fibre length and the imposed average flux respectively. The ranges were as follows a $(0.35$ to $0.5 \mathrm{~mm})$, void fraction (0.35-0.5), fibre length (1.2-2.4 m) and imposed average flux (40$100 \mathrm{Lmh})$. Further details are given in the Appendix.

In equation 36 , the normalised module productivity coefficient is positive for fibre radius, $a$ but negative for void fraction, $\epsilon$ and the fibre length, $L$. It is essentially zero for the imposed average flux, $J_{a v}$. The pattern for the filtration uniformity (equation 37 ) is similar.

\section{Concluding remarks}

A realistic PDI hollow fibre model with finite fibre wall thickness has been developed. The model helps one to understand the influence of the geometric parameters upon the hydrodynamics and the associated filtration process. The results suggest that a hollow fibre module made with moderate void fraction ( 0.35 to 0.45 ), a reasonable inner radius ( 0.4 to $0.45 \mathrm{~mm}$ ) and fibre lengths between $1.2 \mathrm{~m}$ and $1.8 \mathrm{~m}$ will ensure a balanced trade-off between module productivity and overall filtration uniformity. These values accord with industrial practice that has evolved over the last 20 years and this validates our model. In practice the fibre wall thickness is usually designed together with the fibre inner radius with the former being around $2 / 3$ rds of the latter. Table 3 summarised the results.

The optimum range for the imposed average flux will be more apparent once a thorough study on the effect of spatial variations in packing density has been undertaken. Also backwash will be studied in greater detail. For PDI format, backwash is on the outside and the assumption of a uniform distribution of fibres across a cross-section of a module is unrealistic. In future research, allowance will be made for these factors thus enabling simulation of the overall filtration cycle. 


\section{Nomenclature}

\begin{tabular}{|c|c|}
\hline \multicolumn{2}{|c|}{ Letters } \\
\hline$a$ & fibre inside radius $(\mathrm{mm})$ \\
\hline$b$ & fibre outside radius $(\mathrm{mm})$ \\
\hline $\begin{array}{lc}c \\
\end{array}$ & radius of imaginary circular boundary of each fibre $(\mathrm{mm})$ \\
\hline$d_{i}$ & fibre inside diameter $(\mathrm{mm})$ \\
\hline$d_{o}$ & fibre outside diameter $(\mathrm{mm})$ \\
\hline$J$ & permeate flux across the membrane walls (Lmh) \\
\hline$J_{a v}$ & imposed average flux (Lmh) \\
\hline$k$ & permeability $\left(\mathrm{m}^{2}\right)$ \\
\hline$k_{d}$ & dimensionless permeability as defined in previous study [8] \\
\hline$k_{m}$ & permeance (Lmh/bar) \\
\hline 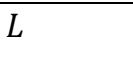 & fibre length $(\mathrm{m})$ \\
\hline$p$ & pressure in lumen side $(\mathrm{kPa})$ \\
\hline$q$ & pressure in shell side $(\mathrm{kPa})$ \\
\hline$\dot{Q}$ & inlet flow: $Q=2 \pi a L J_{a v}=\pi a^{2} w_{0}\left(\mathrm{~m}^{3} / \mathrm{s}\right)$ \\
\hline$r$ & distance along radial direction in each hollow fibre \\
\hline$R e$ & Reynolds number \\
\hline$R_{m}$ & membrane resistance $\left(\mathrm{m}^{-1}\right)$ \\
\hline TMP & transmembrane pressure difference $(\mathrm{kPa})$ \\
\hline$u$ & velocity in $r$ direction $(\mathrm{m} / \mathrm{s})$ \\
\hline$\dot{V}_{c}(\%)$ & cumulated filtration volume percentage \\
\hline$w$ & velocity in $z$ direction $(\mathrm{m} / \mathrm{s})$ \\
\hline$z$ & Distance along fibre length direction (m) \\
\hline \multicolumn{2}{|c|}{ Greek letters } \\
\hline$\beta$ & normalized module productivity \\
\hline
\end{tabular}




\begin{tabular}{|l|l|}
\hline$\gamma$ & shell side area to lumen side area ratio: $\gamma=\left(c^{2}-b^{2}\right) / a^{2}$ \\
\hline$\Gamma$ & fibre wall thickness (mm) \\
\hline$\delta$ & fibre inside radius to fibre length ratio: $\delta=a / L$ \\
\hline$\epsilon$ & module void fraction: $\epsilon=\left(c^{2}-b^{2}\right) / c^{2}$ \\
\hline$\mu$ & Fluid viscosity (Pa s) \\
\hline$\rho$ & fluid density (kg/m $\left.{ }^{3}\right)$ \\
\hline$\phi$ & filtration uniformity parameter \\
\hline
\end{tabular}

\section{Acknowledgements}

Q.X. gratefully acknowledges financial support from the China Scholarship Council.

\section{References}

[1] L. Vera, E. González, O. Díaz, R. Sánchez, R. Bohorque, and J. Rodríguez-Sevilla, "Fouling analysis of a tertiary submerged membrane bioreactor operated in deadend mode at high-fluxes," Journal of Membrane Science, vol. 493, pp. 8-18, 2015.

[2] E. Zondervan and B. Roffel, "Modeling and optimization of membrane lifetime in dead-end ultra filtration," Journal of Membrane Science, vol. 322, pp. 46-51, Sep 1 2008.

[3] M. R. Doshi, W. N. Gill, and V. N. Kabadi, "Optimal Design of Hollow Fiber Modules," Aiche Journal, vol. 23, pp. 765-768, 1977.

[4] G. Pearce, "Pre-treatment of Bio-fouling Prone Seawater Feeds by Membrane Filtration; Strategies to Control and Mitigate the Occurrence of Fouling," Desalination, 2016.

[5] G. K. Pearce, UF/MF Membrane Water Treatment: Principles and Design: Water Treatment Academy Bangkok, 2011.

[6] S.-H. Yoon, Membrane bioreactor processes: Principles and applications: CRC Press, 2015.

[7] A. J. Gijsbertsen-Abrahamse, E. R. Cornelissen, and J. A. M. H. Hofman, "Fiber failure frequency and causes of hollow fiber integrity loss," Desalination, vol. 194, pp. 251258, Jun 102006.

[8] J. G. Herterich, Q. Xu, R. W. Field, D. Vella, and I. M. Griffiths, "Optimizing the operation of a direct-flow filtration device," Journal of Engineering Mathematics, pp. 1-17, 2016. 
[9] B. Blankert, B. H. L. Betlem, and B. Roffel, "Dynamic optimization of a dead-end filtration trajectory: Blocking filtration laws," Journal of Membrane Science, vol. 285, pp. 90-95, Nov 152006.

[10] R. W. Field and G. K. Pearce, "Critical, sustainable and threshold fluxes for membrane filtration with water industry applications," Advances in Colloid and Interface Science, vol. 164, pp. 38-44, May 112011.

[11] C. Serra, M. J. Clifton, P. Moulin, J. C. Rouch, and P. Aptel, "Dead-end ultrafiltration in hollow fiber modules: Module design and process simulation," Journal of Membrane Science, vol. 145, pp. 159-172, Jul 81998.

[12] M. Soltanieh and W. N. Gill, "A Note on the Effect of Fiber Length on the Productivity of Hollow Fiber Modules," Chemical Engineering Communications, vol. 22, pp. 109113, 1983.

[13] Y. J. Kim, T. Yun, S. Lee, P. K. Park, and J. S. Park, "Modeling a full-scale hollow fiber membrane module: Effect of fiber and module dimensions," in Water Quality Technology Conference and Exposition 2012, 2012.

[14] Y. J. Kim, T. Yun, J. Han, S. Lee, P. K. Park, B. K. Hwang, et al., "Design optimization of ultrafiltration membrane module for desalination applications," Desalination and Water Treatment, vol. 43, pp. 291-297, Apr 2012.

[15] J. Wang, Z. Cui, H. Jia, and H. W. Zhang, "The effect of fiber length on non-uniform and hysteresis phenomenon in hollow fiber membrane backflushing," Desalination, vol. 337, pp. 98-108, Mar 172014.

[16] X. H. Li, J. X. Li, H. Wang, X. X. Huang, B. Q. He, Y. H. Yao, et al., "A filtration model for prediction of local flux distribution and optimization of submerged hollow fiber membrane module," Aiche Journal, vol. 61, pp. 4377-4386, Dec 2015.

[17] S. H. Yoon, H. S. Kim, and I. T. Yeom, "Optimization model of submerged hollow fiber membrane modules," Journal of Membrane Science, vol. 234, pp. 147-156, May 1 2004.

[18] J. Gunther, P. Schmitz, C. Albasi, and C. Lafforgue, "A numerical approach to study the impact of packing density on fluid flow distribution in hollow fiber module," Journal of Membrane Science, vol. 348, pp. 277-286, Feb 152010.

[19] J. Gunther, D. Hobbs, C. Albasi, C. Lafforgue, A. Cockx, and P. Schmitz, "Modeling the effect of packing density on filtration performances in hollow fiber microfiltration module: A spatial study of cake growth," Journal of Membrane Science, vol. 389, pp. 126-136, Feb 12012.

[20] S. Chang, A. G. Fane, and T. D. Waite, "Analysis of constant permeate flow filtration using dead-end hollow fiber membranes," Journal of Membrane Science, vol. 268, pp. 132-141, Jan 152006.

[21] M. Mondor and C. Moresoli, "Effect of fiber lumen radius on the permeate flux of hollow fiber membrane modules," Desalination, vol. 191, pp. 365-370, 2006.

[22] W. J. C. V. de Ven, K. van't Sant, I. G. M. Punt, A. Zwijnenburg, A. J. B. Kemperman, W. G. J. van der Meer, et al., "Hollow fiber dead-end ultrafiltration: Axial transport variations during humic acid filtration," Journal of Membrane Science, vol. 314, pp. 112-122, Apr 302008.

[23] H. J. Oh, J. S. Choi, B. B. Choi, S. Lee, and T. M. Hwang, "Effect of axial variation of flux on filtration characteristics of hollow fiber membrane for drinking water treatment," in Water Science and Technology: Water Supply vol. 7, ed, 2007, pp. 95-101. 
[24] J. Happel, "Viscous Flow Relative to Arrays of Cylinders," Aiche Journal, vol. 5, pp. 174-177, 1959.

[25] S. Elmore and G. G. Lipscomb, "Analytical Approximations of the Effect of a Fiber Size Distribution on the Performance of Hollow-Fiber Membrane Separation Devices," Journal of Membrane Science, vol. 98, pp. 49-56, Jan 131995.

[26] C. Baley, "Analysis of the flax fibres tensile behaviour and analysis of the tensile stiffness increase," Composites Part a-Applied Science and Manufacturing, vol. 33, pp. 939-948, 2002.

[27] R. W. Field, D. Wu, J. A. Howell, and B. B. Gupta, "Critical Flux Concept for Microfiltration Fouling," Journal of Membrane Science, vol. 100, pp. 259-272, Apr 28 1995.

[28] G. Taguchi and G. Taguchi, "System of experimental design; engineering methods to optimize quality and minimize costs," 1987.

[29] Q. Xu, Q. F. Qian, A. Quek, N. Ai, G. N. Zeng, and J. W. Wang, "Hydrothermal Carbonization of Macroalgae and the Effects of Experimental Parameters on the Properties of Hydrochars," Acs Sustainable Chemistry \& Engineering, vol. 1, pp. 10921101, Sep 2013.

\section{Appendix}

Typical values of the four variables, taken from industrial practice are displayed in Table A1 [5]. As there are 4 parameters influencing the overall filtration performance and each parameter corresponds to at least 4 levels, a traditional approach could involve at least $256\left(4^{4}\right)$ different sets of calculation. Taguchi Method [28] is applied so as to simplify the investigation process. A similar Taguchi approach has been applied by $\mathrm{Xu}$ et al. [29] to replace an original set of 1024 experiments with a set of 16 . Before applying their experimental design method to our study, each control factor was individually examined to determine the parameters' range. Based upon the typical applied range given in Table A1 values shown in Table A2 were chosen so as to apply Taguchi design method. The investigation of 4 different levels of the 4 control parameters (Table A2) are then readily assigned to 16 runs by the orthogonal array $L_{16}\left(4^{4}\right)$ as shown in Table A3. The results are given in the main text.

Table A1 Control parameters and their industrially relevant range

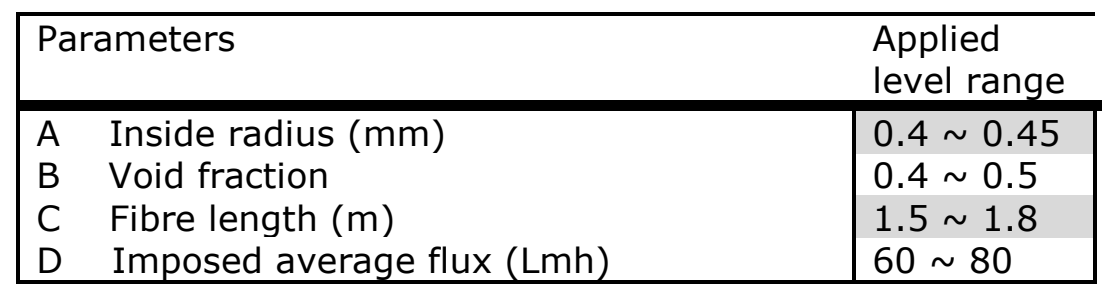


Table A2 Control parameters and their levels used in this study

\begin{tabular}{|llllll|}
\hline Parameters & Level & Level & Level & Level \\
& & 1 & 2 & 3 & 4 \\
\hline A & Inside radius $(\mathrm{mm})$ & 0.35 & 0.4 & 0.45 & 0.5 \\
B & Void fraction & 0.35 & 0.4 & 0.45 & 0.5 \\
C & Fibre length $(\mathrm{m})$ & 1.2 & 1.6 & 2.0 & 2.4 \\
D & Imposed average flux $(\mathrm{Lmh})$ & 40 & 60 & 80 & 100 \\
\hline
\end{tabular}

Table A3 $L_{16}\left(4^{5}\right)$ Orthogonal Array of Taguchi research control parameters

\begin{tabular}{llllllllll}
\hline row & Run & A & B & C & D & $\begin{array}{l}\text { Inside } \\
\text { radius } \\
\text { (mm) }\end{array}$ & $\begin{array}{l}\text { Void } \\
\text { fraction }\end{array}$ & $\begin{array}{l}\text { Fibre } \\
\text { length } \\
(\mathrm{m})\end{array}$ & $\begin{array}{l}\text { Imposed } \\
\text { average } \\
\text { flux } \\
\text { (Lmh) }\end{array}$ \\
\hline 1 & 1 & 1 & 1 & 1 & 1 & 0.35 & 0.35 & 1.2 & 40 \\
2 & 5 & 1 & 2 & 2 & 2 & 0.35 & 0.4 & 1.6 & 60 \\
3 & 9 & 1 & 3 & 3 & 3 & 0.35 & 0.45 & 2.0 & 80 \\
4 & 13 & 1 & 4 & 4 & 4 & 0.35 & 0.5 & 2.4 & 100 \\
5 & 10 & 2 & 1 & 2 & 3 & 0.4 & 0.35 & 1.6 & 80 \\
6 & 14 & 2 & 2 & 1 & 4 & 0.4 & 0.4 & 1.2 & 100 \\
7 & 2 & 2 & 3 & 4 & 1 & 0.4 & 0.45 & 2.4 & 40 \\
8 & 6 & 2 & 4 & 3 & 2 & 0.4 & 0.5 & 2 & 60 \\
9 & 15 & 3 & 1 & 3 & 4 & 0.45 & 0.35 & 2 & 100 \\
10 & 11 & 3 & 2 & 4 & 3 & 0.45 & 0.4 & 2.4 & 80 \\
11 & 7 & 3 & 3 & 1 & 2 & 0.45 & 0.45 & 1.2 & 60 \\
12 & 3 & 3 & 4 & 2 & 1 & 0.45 & 0.5 & 1.6 & 40 \\
13 & 8 & 4 & 1 & 4 & 2 & 0.5 & 0.35 & 2.4 & 60 \\
14 & 4 & 4 & 2 & 3 & 1 & 0.5 & 0.4 & 2 & 40 \\
15 & 16 & 4 & 3 & 2 & 4 & 0.5 & 0.45 & 1.6 & 100 \\
16 & 12 & 4 & 4 & 1 & 3 & 0.5 & 0.5 & 1.2 & 80 \\
\hline
\end{tabular}

